intertextuality, cohesiveness, wide use of the subtext, creation of the effect of suspense, while most of these features stand as interconnected and as a result of the influence of some language phenomena. These characters and features stand as a tool for the transmission of information (verbal, non-verbal, extralinguistic), assist in the correct interpretation of the speaker's feelings in a certain situation and to understand their vision of this situation, other speakers and the object of discussion. The authors note that all the previously mentioned features one way or another influence and form the structure, style and the perception of the film, and the film text itself is an important milestone in the complex synthetic film structure, alongside with such extralinguistic components, which are crucial to meaningful and aesthetic completeness, as visual information, sound, visual and mechanical special effects, computer graphics, etc. The article explores and draws attention to the importance of the analysis of film discourse and the concept of "film text" in the light of increasing popularity, relevance, influence, and therefore the importance of the art of cinematography, which is treated currently not only as an entertainment, or a part of popular culture, but also as a tool of influence on communication and social cognition, and therefore individually taken movies are an important part of the world film resource and film discourse.

Key words: film discourse, subtext, suspense, intertextuality, language code.

DOI: https://doi.org/10.32782/2410-0927-2020-12-21

УДК $811.111^{\prime} 22 ’ 42$

Лариса Макарук

\title{
СТРУКТУРА, СЕМАНТИКА ТА ФУНКЦЙНЕ ПРИЗНАЧЕННЯ ДУЖОК ТА ЦИФР У СУЧАСНОМУ АНГЛОМОВНОМУ МАСМЕДІЙНОМУ КОМУНІКАТИВНОМУ ПРОСТОРІ
}

У роботі проаналізовано дужки та цифри як невербальні елементи, що є складниками однієї з груп, які загалом охоплюють невербальні та паравербальні компоненти, які функціонують у сучасному англомовному масмедійному комунікативному просторі. До аналізованої нами групи «Непіктографічні та нефотографічні елементи» входять знаки пунктуації; діакритичні знаки; типографічні й інші допоміжні знаки; цифри (числа); математичні символи; абревіатури. У цій розвідці докладно висвітлено специфіку дужок та цифр як інтегральних модусів масмедійного середовища.

Окреслено їх семантичні та структурні особливості, ідентифіковано функційне навантаження, обгрунтовано їх роль та призначення у сучасному англомовному масмедійному комунікативному просторі. Крім традиційного використання круглих дужок як знаків пунктуації у складі тексту, які додатково пояснюють зміст, уточнюють сказане поза текстом в дужках, активно залучають квадратні, фігурні, атипові видозмінені (контекстуально залежні).

Окрім типових функцій, дужки виконують й низку атипових будучи різними за розмірами, формою та кількісним складом, зокрема: уточнювальну, лаконічну, дейктичну, змістово-розгалужувальну, атрактивну, змістовидільну, акцентування уваги, змістотворчу, структурувальну, компресивну, а також указують на ініціальну та фінальну частини тексту.

Встановлено, що в англомовному масмедійному комунікативному просторі цифри використовують замість лексем, графем і морфем. Переважно, вони компресують кількість традиційних графічних елементів, що входять до складу однієї лексеми. Трапляються випадки, коли замість словесного модусу використовують цифровий, який виконує роль лексеми. Цифрові модуси також бувають різних форм та розмірів й мають різне кольорове забарвлення. Виявлено, що найпоширенішим є залучення цифр чотири та два, які заміщують piзні лексеми (for, four, two, to тощо).

Ключові слова: масмедіа, комунікативний простір, дужки, цифри, функція.

Вступ. Закономірно, що науковий опис особливостей масмедійного комунікативного простору як мультимодального явища, в якому співіснують вербальні, невербальні та паравербальні засоби, потребує нових поглядів на функціонування писемного мовлення у прагматичному, соціокультурному і лінгвостилістичному вимірах. У зв'язку з цим особливої значущості набуває всебічне дослідження різних аспектів мультимодальності сучасного спілкування, дослідженню яких присвячені роботи вітчизняних і зарубіжних учених, зокрема Дж. Беземера [6], К. Джевіт [7], Г. Кресса [8], Т. ван Лівена [11], С. Норріс [9], К. О’Халлоран [10], В. А. Єфименко [3], М. А. Карп [4], О. В. Білецька [1], О. С. Маріна [5], Н. Я. Град [2].

Незважаючи на значну кількість розвідок, присвячених масмедійній царині, відкритим залишається питання про структурно-функційні, комунікативно-прагматичні, лінгвостилістичні та соціокультурні аспекти взаємодії вербальних, невербальних і паравербальних засобів, що й

(C) Макарук Л., 2020 
зумовлює актуальність обраної проблематики. Графічні компоненти, які функціонують в масмедіа поділено на кілька груп: сегментація тексту та графічні процеси; шрифт і колір; непіктографічні та нефотографічні елементи; іконічні елементи (зображення); інфографіка.

Групу «Непіктографічні та нефотографічні елементи», поділяємо на: знаки пунктуації (крапка, кома, крапка $з$ комою, знак оклику, знак питання, двокрапка, одиничні та подвійні лапки, дужки (круглі, квадратні, фігурні (однокомпонентні, двокомпонентні)), тире, апостроф, дефіс); діакритичні знаки (акут, циркумфлекс, гравіс, знак наголосу, макрон, тильда тощо); типографічні й інші допоміжні знаки; цифри (числа); математичні символи; абревіатури, що поєднують виключно невербальні одиниці чи вербальні й невербальні складники одночасно.

У цій розвідці докладно обгрунтуємо специфіку функціонування дужок та цифр як поліфункційних елементів, що є інтегральними складниками масмедійного комунікативного простору.

Мета роботи полягає у визначенні семантичного навантаження та ідентифікації функційного призначення дужок та цифр як інтегральних складників масмедійного писемного мовлення та зумовлює потребу у розв'язанні таких завдань:

- здійснити вибірку ілюстративного матеріалу в англомовних періодичних виданнях;

- виокремити елементи різних груп загалом та компоненти, які входитимуть до групи «Непіктографічні та нефотографічні елементи» зокрема;

- проаналізувати дужки та цифри 3 урахуванням їх структури, семантики та функційного навантаження.

Методи та методики дослідження. Підгрунтям для дослідження сучасного англомовного масмедійного комунікативного простору стала теоретико-методологічна база паралінгвістики, графічної лінгвістики, візуальної лінгвістики, концепції мультимодальної грамотності. У роботі розроблено алгоритм дослідження сучасного англомовного масмедійного комунікативного простору й обгрунтовано доцільність використання системної методики, зорієнтованої на покрокове емпіричне виявлення взаємодії вербальних, невербальних i паравербальних засобів. Методика містить кілька взаємопов'язаних етапів. Так, на першому етапі шляхом використання методу суцільної вибірки було сформовано корпус ілюстративного матеріалу. На другому етапі, спираючись на описовий метод та методи індукції, дедукції, аналізу й синтезу, було проаналізовано виявлені засоби, здійснено інвентаризацію та систематизацію невербальних i паравербальних компонентів. На третьому етапі застосовано метод дистрибутивного аналізу, який уможливив формування найбільш частотних оточень невербальних та паравербальних компонентів, що функціонують в англомовному масмедійному комунікативному просторі. Четвертий етап зорієнтований на ідентифікацію функційного призначення та визначення ролей невербальних і паравербальних засобів із розкриттям їх значень, можливих сполучуваностей та врахуванням соціальних параметрів. На цьому етапі було застосовано соціо-семіотичний i системно-функційний методи. Використання геосеміотичного підходу на п'ятому етапі дало змогу докладно проаналізувати ілюстративні компоненти невербальної природи, виявивши їx взаємозв'язок i взаємозалежність iз вербальними одиницями. В основі шостого етапу лежать порівняльний і контекстологічний методи, які уможливили ідентифікацію спільних та відмінних ознак невербальних i паравербальних компонентів та дали змогу з'ясувати значення аналізованих компонентів.

Результати та дискусії. В англомовному масмедійному просторі особливу роль відіграють дужки та цифри, які мають різну структуру, семантичне навантаження та, як свідчить проведений аналіз, є поліфункційними елементами. Передусім зазначимо, що, класично під дужками розуміють дві конвенційні позначки визначеної форми та розмірів, регульовані автоматично у Microsoft Word. Відповідно до категорії числа дужки - це множина. Однак поширена тенденція залучення лише однієї дужки (правої або лівої) чи двох (праві або ліві). Розглянемо означені варіації детальніше.

Аналізуючи круглі дужки, зауважимо, що найчастотніше в англомовному комунікативному просторі вони виконують роль уточнення і $є$ частиною тексту. Наприклад, 
Mary, Queens of Scots was an enthusiast; her clubs were carried by students she called "cadets" (now known as "caddies") [30, c. 108].

Трапляються випадки, коли у дужках подано окреме речення: Which makes sense, since Hyland is also an artist. (His painting of Horak Zsolt, a friend of his in Budapest, is at far right.) he also loves a party, and the T staff would often repair to his little penthouse aerie, where we always felt as if it were at a Holy Golightly cocktail hour, not the least because his cat, Rocco (center), has retro movie star qualities [21, c. 4]. В аналізованому випадку дужки можна вважати графічним маркером, що слугує оболонкою для уточнення, скеровує читача до певних об'єктів, вказує, яке фото ілюструє вербальний опис (рис. 1-2).

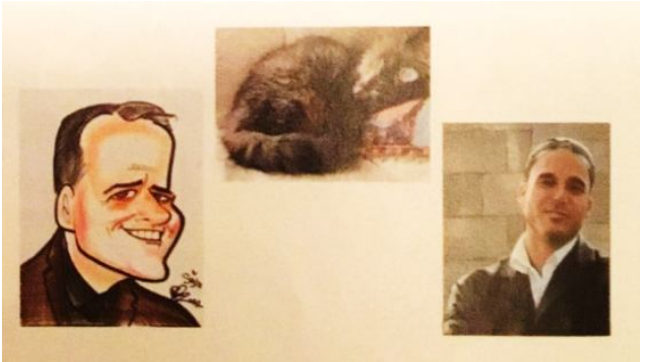

Рис. $1[20$, с. 16$]$

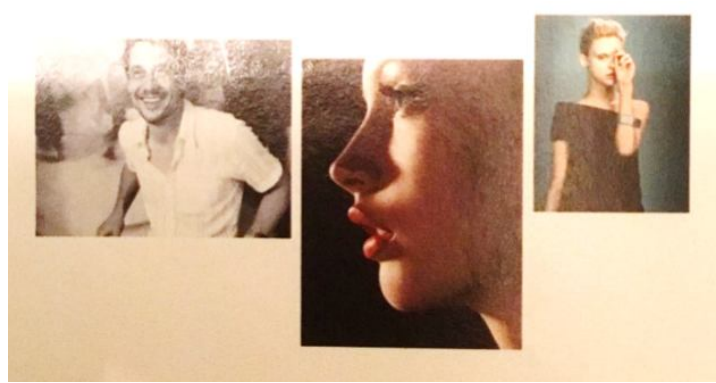

Рис. 2 [20, с. 16]

Наведемо інший приклад: The larger-than-life Italian design wizard Carlo Mollino was the muse for "Absolute Fabulist" (Page 68), shot by the photographer David Slijper [20, с. 18]. Як спостерігаємо, автор кілька разів послуговується дужками. У першому прикладі інформація «прокладає шлях» розкриття висловленого до дужок, вказує сторінку журналу, на якій власне розміщена вказана стаття.

У випадку, якби не було цього графічного компонента в тексті, авторові довелося б відійти від обраної стратегії лаконічності та детальніше розкрити зміст. Однак такий формат дає змогу добре й швидко зрозуміти, де можна знайти інформацію про “Absolute Fabulist”. Дужки в аналізованому контексті сприяють логічній компресії тексту.

Наведемо ще один приклад: A regular contributor to the magazines $W$ (center) and 10 (far right), Slijper says he hopes to travel down new roads with his next photographic series, literally [22, c. 4]. Він безпосередньо стосується наведеного зображення. Описуючи журнали, автор демонструє фотосвітлини, вказуючи їх локацію на сторінці поруч із текстом, скеровуючи читача до унаочненого матеріалу.

Це також розширює межі запропонованого вербального складника, дає змогу візуально побачити те, про що конкретно йдеться, й за рахунок невербального засобу збільшує не лише об'єм тексту, але й його семантичне наповнення. Вважаємо, що дужки тут доречні. Зауважимо, що у разі їх відсутності виникло б питання про доцільність зображень, розміщених поруч. Однак фотознімки підписані, розміщені горизонтально й ледве помітні через мінімалістичний кегль.

Щодо фігурних дужок, то, як зображено і на рис. 3 і 4, і в корпусі фактичного матеріалу їх не використовують у загальному тексті як графічні вкраплення в межах лінійної вербальної канви. Помилковим було б твердження про те, що вони не є частиною англомовного простору. Власне дужки одні з його структурних елементів і покликані виконати певну функцію. Рис. 3 підтверджує висловлені міркування, оскільки, розглядаючи повністю мультимодальний масмедійний текст, бачимо, що найважливішу, на думку автора статті, інформацію розміщено посередині шпальти з коротким вербальним супроводом, який дає змогу зрозуміти зміст. Крім атрактивної функції, фігурні дужки також виконують змістовидільну й уточнювальну, оскільки $\epsilon$ графічним засобом обрамлення частини мультимодального тексту й змушують читачів зосередити увагу саме на частині, що підлягає графічному маркуванню. Вони також чітко вказують на ініціальну та фінальну частини тексту. 


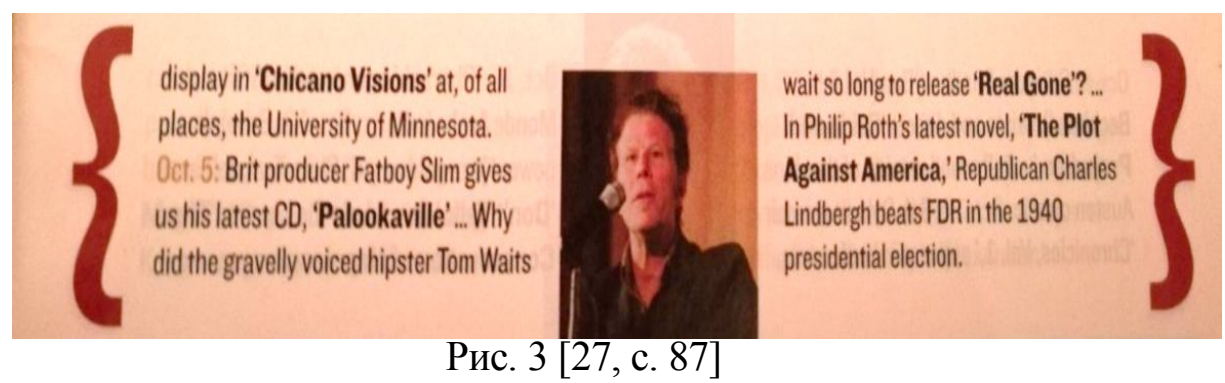

Рис. 4 відмінний від попереднього тим, що містить дві фігурні праві дужки. Таку варіацію спостерігаємо в назві рубрики. На іiі початку розміщений орел як символ американської лінгвокультури. Назва вміщує два накреслення шрифту: курсив друкований, у двох правих дужках подано другу частину назви Culture Club. Ці графічні маркери, окрім форми та кеглю, нічим не примітні й виконують роль традиційних круглих чи менш поширених квадратних дужок, оскільки у них подано коротку вербальну конструкцію, яку можна вважати частиною заголовку “Your Independent Culture Club" або "Your Independent. Culture Club”.

Поділяючи обидва припущення, висловимо міркування на користь останнього. Причиною цього вважаємо дужки, які, з одного боку, не ускладнюють процес читання, а 3 іншого - сповільнюють його. Ми також схильні вважати, що ці дужки виконують функцію акцентування уваги, оскільки продуценти прагнули наголосити, що йтиметься саме про Culture Club у виданні "Independent".

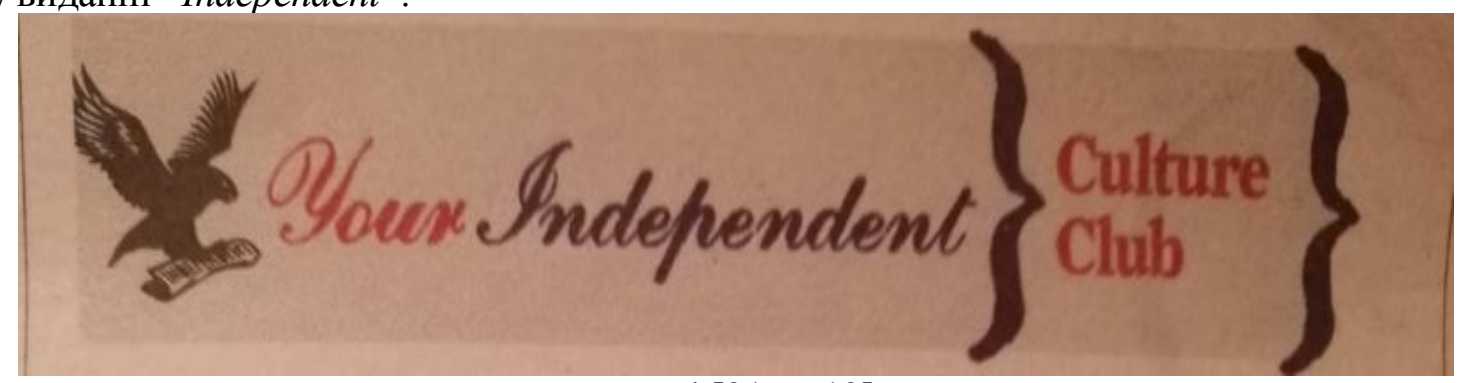

Рис. $4[31$, с. 13$]$

Квадратні дужки на рис. 5 виконують функцію уточнення, деталізуючи авторські ідеї. На наступному рис. 6 дужки за формою й структурою дещо відмінні. Вони містять додаткові декоративні елементи. Якщо в окремих обгрунтованих вище прикладах зміст зрозумілий без інформації в дужках, то в аналізованому контексті зміст речення втрачено. Дужки не $\epsilon$ другорядними, а виступають змістотворчими елементами речення: I don't think [PR is] put on the top of the at most [14, с. 23]. Вони лімітують можливості прочитання.

Така конструкція дає змогу припустити, що автор із певних причин не робить акцент саме на цій частині речення й намагається, щоб читачі ії оминули. Однак це зробити цілком неможливо, оскільки частини одного й того ж речення розміщені у лінійному порядку.

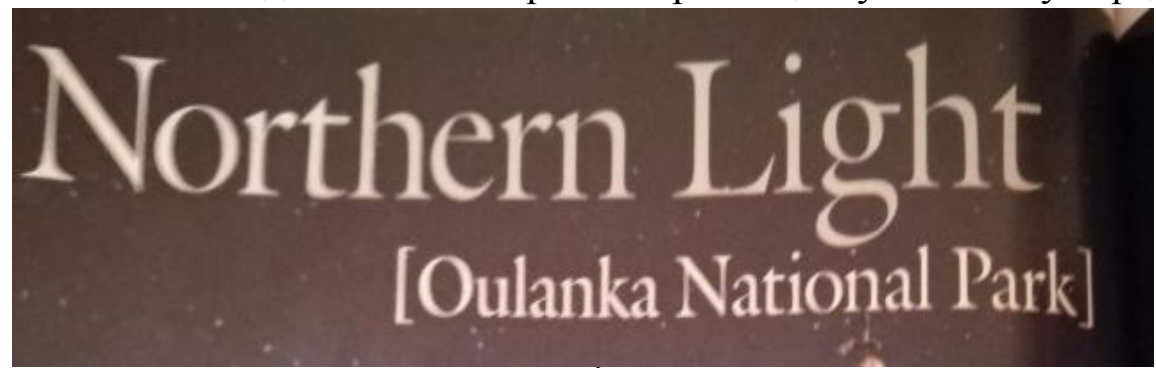

Рис. $5[25$, с. 60$]$

Одинична права дужка на рис. 6 є засобом структурування інформащії. Вона слугує елементом, що поділяє наведений текст на дві половини. Важливіша ліва частина, що підтверджує розмір кеглю. Менш важлива права. Представлений приклад дає змогу стверджувати, що дужка також заміщує частину тексту й виконує функиію компресії. 
Продуценти зробили такий вибір, оскільки без дужки слід було б використати принаймні крапку, а для більш логічної послідовності збільшити текст.

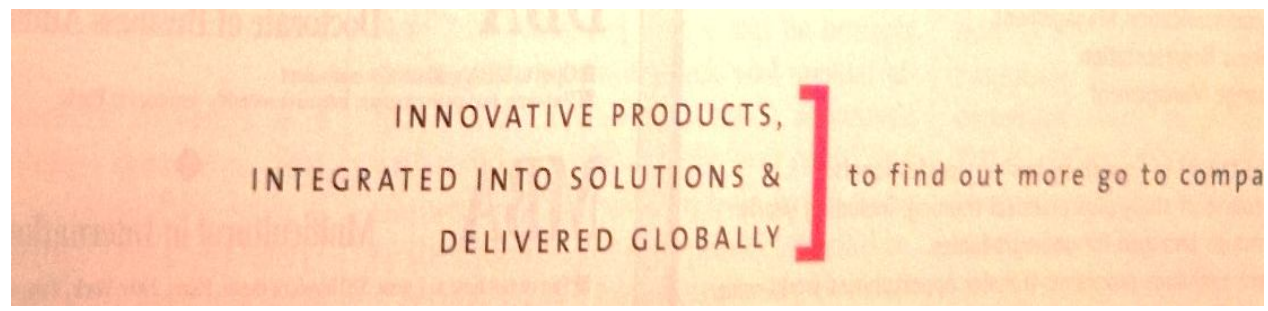

Рис. $6[26$, с. 89$]$

Привертає увагу рис. 7. Елементи, розміщені на ньому, нагадують некодифіковані дужки. Ïх вибір зумовлений стилем написання. Графеми “ $D$ ” та " $G$ ” трансформовані. Їхня форма видозмінена завдяки накресленню. Дотримуючись обраного стилю, дату та місце проведення анонсованого заходу представляють за допомогою дужок, що мають неабияку схожість із аналізованими графемами. Різнолінійна локація таких елементів за допомогою кеглю орієнтує та інформаційно насичує, не ускладнюючи перцепцію, а, навпаки, значно пришвидшує іiі.

Оригінальність обраного стилю свідчить про те, що нетрадиційні дужки теж мають право на існування й здатні не лише естетично репрезентувати інформацію, а й сприяти іiі швидкому прочитанню й відповідно розумінню. Лаконічність та компресивність - невід'ємні функційні ознаки. Такі дужки можна вважати одночасно засобом структурування інформації.

Продемонструємо й інші можливості дужок (рис. 8). Завдяки так званим емотиконам вони досить часто виконують роль посмішки, імітуючи вираз обличчя. Цей елемент на сучасному етапі надто популярний серед комунікантів. Дужка надає рекламі особливого шарму, робить іï живою, “промовляючи" до потенційного читача. "Програвання" назви теж має відповідний ефект.

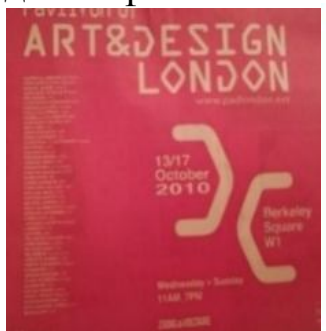

Рис. $7[19$, с. 1$]$
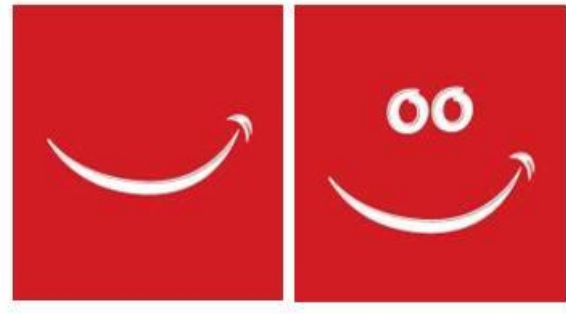

Рис. 8 [12]
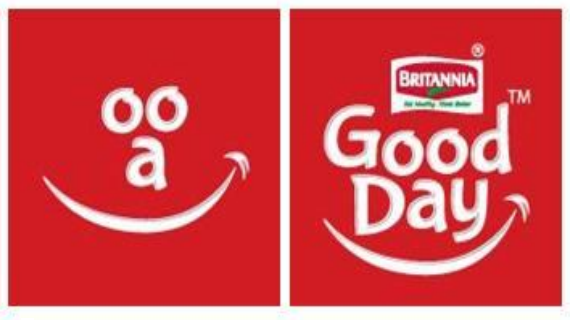

В англомовному комунікативному просторі поряд із вербальними засобами інтенсивно використовують цифровий модус. Його функційне призначення різне. Це залежить від кожного конкретного випадку. Часто поруч із цифрами спостерігаємо інші умовні позначки або скорочення, які можуть бути розміщені і спочатку, i в кінці. Водночас у сучасному англомовному світі цифри покликані замінити лексеми й додати текстовому фрагменту бажаної колоритності, компресуючи його зміст. Поширені випадки, коли цифри використовують у вербальному оточенні. Замість них могла б бути звичайна лексема. Рис. 9 демонструє кілька способів сполучуваності числового й вербального модусів: A bed so sumptuous it's been 100 years in the making [32, с. А23]. Усталеною є стратегія залучення цифр у поштових адресах (Harrods, KnightsBridge SW1; Solo9W57). Номери телефонів в уяві насамперед асоційовані з числами (рис. 9). Підтвердженням, що стосується дистрибуції, слугує приклад SINCE 1905 [17, с. 3].

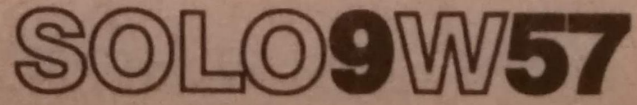

SOLOW BUILDING COMPANY

Рис. 9 [12, с. А23] 
В англомовному комунікативному просторі цифри покликані репрезентувати:

- вік (Lily Wiletts, 27, was on her way to Blackpool with partner Sam Wadsworth, 26, when a tanker caught fire, bringing the M62 to a halt [32, c. D6]; Last year, an 88-year-old woman was admitted to NYU Langone Medical Center in a nearly comatose state, unable to walk or swallow and bearly able to breathe [32, c. D6];

- час (Mum-of two Lily grabbed a blanket from the back of their Citroen Dispatch and lay on the sweltering tarmac for about 20 minutes [23, c. 75 ]);

- кількість (estimates range from 14,500 to 18,100 [23, с. 75]); (“War, war, war! " roared the 5, 000 volunteers of the January 3d Division of Blackshirts; and then, "Duce! Duce! Duce!" Never before during the six-month period of strained relations between Italy and Abyssinia had his followers heard Mussolini call for war [23, c. 75 ]);

- дату (роки) (100, 75, 50 YEARS AGO; 1910 Servant Problem Solved); After opening in 1982, avant garde Manchester nightclub the Haçienda lost money hand over fist for years [19, c.17]; The same is true of the shocks of '86 and '91; they were passing events [19, c. 17].

- дату (місяць та день) (The farthest Mussolini had gone heretofore was this public speech of May 24, when he said: "We are circumspect about the decision, but once the decision is made we will never turn back." [18, c. 18] ; Attend the Asti D.O.C.G.: Multi-Sensory Experience, a three-day program featuring tastings and seminars, October $13^{\text {th }}-14^{\text {th }}-15^{\text {th }}[18$, c. 5$\left.]\right)$;

- дату (день, місяць, рік) (The Moment I|26|09: Poeria [37, с. 11]);

- грошові еквіваленти (With a minimum charge of 20 cents a day for a small family, a service company has been formed to wash the dishes of tenants of apartment houses [18, c. 27]);

- вартість (According to a recent study by Yahoo Travel and Harris Interactive, 75 percent of Americans plan to travel this summer, with the average household spending more than $\$ 1,700[18$, c. 13]).

Сполучуваність цифр та символів проілюстровано на рис. 10. Цифри й лапки 43” репрезентують діагональ екрана, цифри й символи, які позначають британську валюту, пропонуючи дві ціни - до і після зниження вартості товару. Для позначення вищої ціни, яка не $\epsilon$ валідною, використано закреслення як один із прийомів та технік графічного оформлення, що дає змогу лаконічно подати інформацію без залучення словесних еквівалентів.

Рис. 11, окрім аналогічного поєднання цифр та грошових символів зображує $20 G B$ як вказівка на кількість доступного Інтернету за означену вартість. Як бачимо, поширена тенденція використання чисел та інших знаків або літерних абревіатур може передувати і наслідувати кількісні показники.

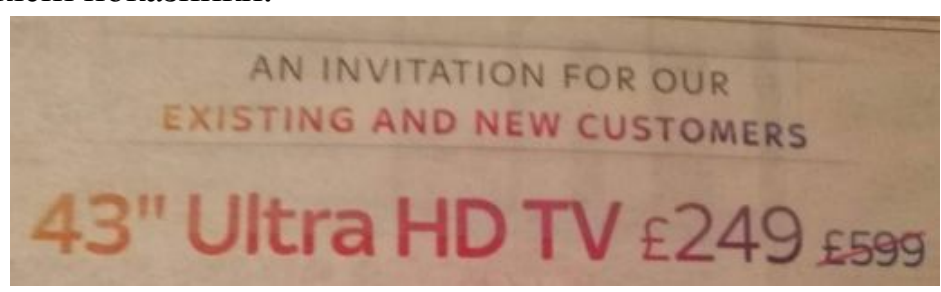

Рис. 10 [34, с. 23]

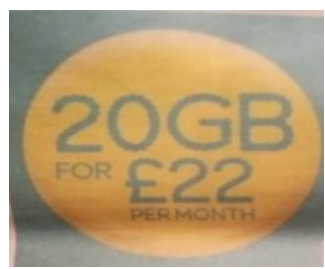

Рис. $11[34$, с. 8$]$

Очевидне використання позначки, що замінює вербальну одиницю - percentage (відсотки): $75 \%$ Off Installation [25, с. 3]. This could improve fuel emissions by $45 \%$ [25, с. 3]. Однак в англомовному комунікативному просторі трапляються такі випадки, коли вищезазначений символ позначений лексичним еквівалентом: According to a recent study by Yahoo Travel and Harris Interactive, 75 percent of Americans plan to travel this summer, with the average household spending more than \$1, 700 [18, с. 32]. Характерне для англомовного масмедійного простору використання чисел, дефісів та лексем (в однині): World's 5-star airline [18, с. 34]; Sign up now for the 3-Month Cash Back Bonus [18, с. 21]. Типовими є також такі комбінації:

- залучення цифр і слешу, скерованого вправо pre-9 / 11 days [19, с. 28]; (...cheap airline tickets will continue to drive tourism from America above and beyond the pre-9/11 days [19, c. 35]);

- використання цифр й буквосполук th для репрезентації дат: Asti D.O.C.G. invites you to visit the following locations on October 12th \&13th and 19th \&20th to enjoy a complimentary glass of Asti and a chance to win a trip to romantic Italy [15, c. 24]). 
В англомовних засобах масової комунікації значний відсоток медійного простору охоплюють інформаційні блоки, у яких детально й полівекторно висвітлено новини фінансових ринків. На рис. 12 і 13 використано цифри, що відображають стан кредитних ринків у різних валютних еквівалентах. Фінансовий приріст компаній продемонстровано за допомогою цілих та дробових чисел (рис. 13). Числа з сотими та десятими розмежовані крапками. Позитивну фінансову динаміку проілюстровано арифметичним знаком +, негативну-.

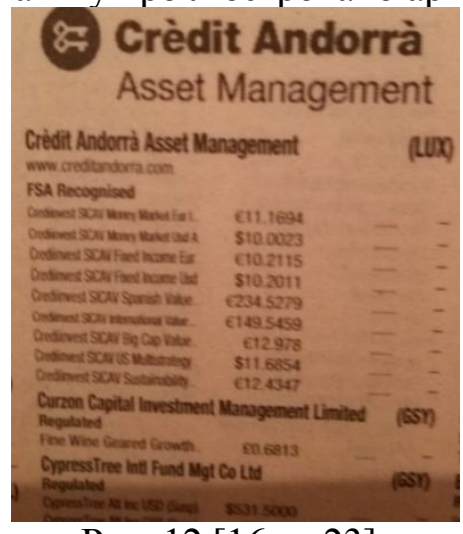

Рис. 12 [16, с. 23]

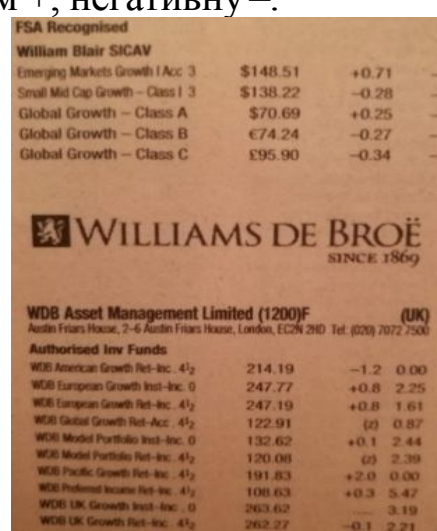

Рис. $13[16$, с. 26$]$

Однією із поширених тенденцій у сучасному англомовному комунікативному просторі $\epsilon$ використання літери та цифри поруч. Наприклад, “Traffic tan on M 62", "Citroën starts to answer all the questions as C5 raises expectations" [35, c. 96]. Аналіз свідчить, що схильність рекламодавців до використання цифр замість лексем набуває ознак тенденційності (рис. 14 та рис. 15).

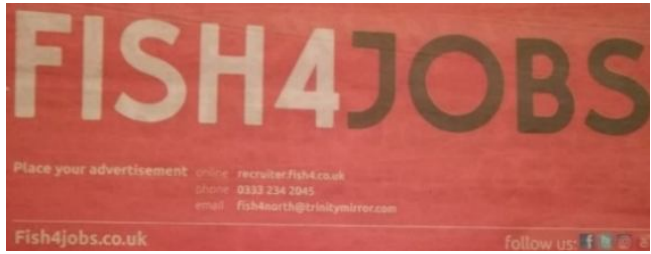

Рис. $14[15$, с. 38$]$

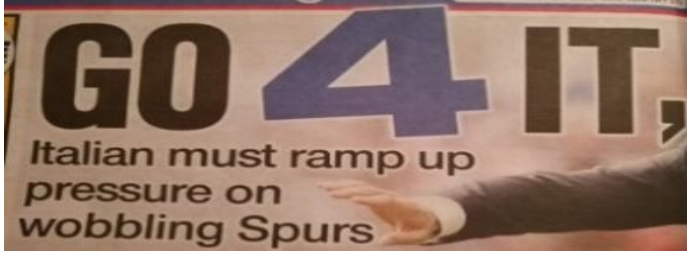

Рис. 15 [33, с. 100]

Вартими уваги у цьому аспекті є рис. 3.94 та рис. 3.95, на одному з яких простежуємо кореляцію вербальних і невербальних компонентів. Двійка є еквівалентом лексем $t w o$ та $t o$, іноді ïx частин (to), незважаючи на те, що спелінг цифри - two. Крім того, на рис. 17 вона «підносить префікс есо до квадрату», що підсилює значення слова екологічний. Розуміємо, що цей транспортний засіб екологічно чистий, удвічі чистіший за інші. Рис. 16 підлягає такому дешифруванню: essential to energy.

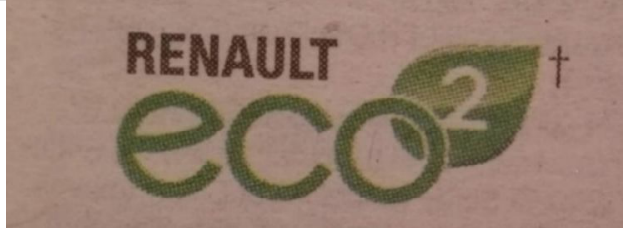

Рис. 16 [24, с. 39]

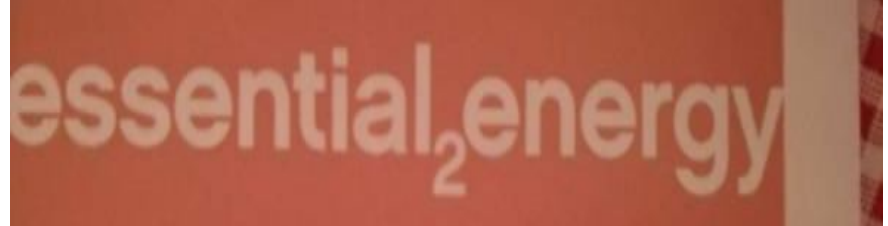

Рис. 17 [29, с. 20]

Неможливо залишити поза увагою й наступний приклад (рис. 18), оскільки це один із найбільш неординарних випадків із цифровим модусом, ідентифікований в англомовному комунікативному просторі. Знижка на продукти харчування виражена кількома модусами: цифровим, ілюстративним (тарілка зі стравою), математичним символом (\%) та вербальним.

Функцію цифри “0” виконує тарілка, доповнена цифрою 5, що вказує на знижку 50 \%. Таке “сплетіння" кількох модусів максимально зближує читача зі світом реклами, де за допомогою засобів графіки уявне стає реальним, близьким для свідомості.

На рис. 19 представлено рекламу косметичного засобу, який, як свідчать графічні репрезентанти, настільки ефективний, що здатний забезпечити його користувачеві 48 годин 
впевненості. Поєднання кількох модусів в єдине ціле (зображувального у формі годинника, співвідносного з цифровим та вербальним) дає змогу ідентифікувати правомірну семантику, провівши паралелі ефективного рекламного засобу із чіткістю роботи годинників.

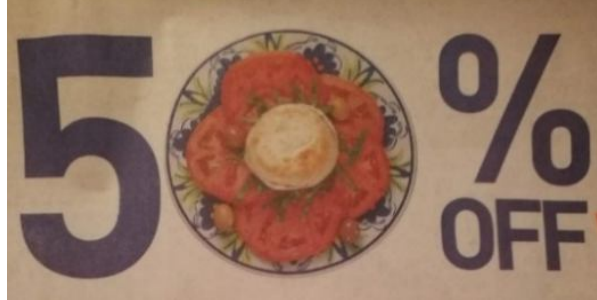

Рис. $18[28$, с. 13$]$

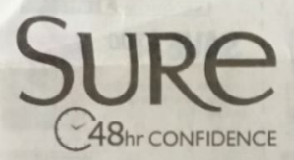

INFINITELY SURE

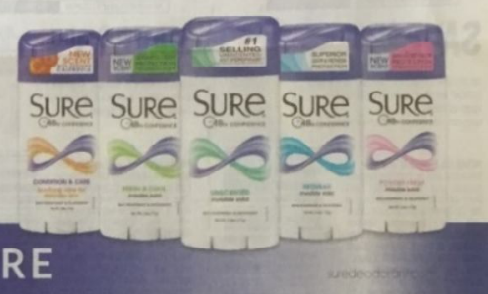

Рис. 19 [13]

Підтвердження поширеної тенденції використання цифр, які виконують роль повноцінної лексеми, знаходимо на рис. 20 Замість for залучено цифровий модус 4. Лексеми four та for не співпадають ні за семантикою, ні за графічним вираженням, однак успішно виконують покладені на них трансформовані функції.

Вимова одного і другого (транскрипційне відображення) теж має розбіжності, якими певною мірою можна було б знехтувати, однак заміна однієї лексеми на іншу призвела б до правомірності семантичного змісту речення. Отже, цифровий модус нівелює ці неточності та асимілює один варіант прочитання до іншого. Сполучення вербального та невербального (цифрового модусу) на рис. 21 вказує на ціну, за яку можна придбати другу одиницю рекламованого товару ( $2^{\text {nd }}$ BOX ONLY 10 c $[13$, c. 32$]$ ).

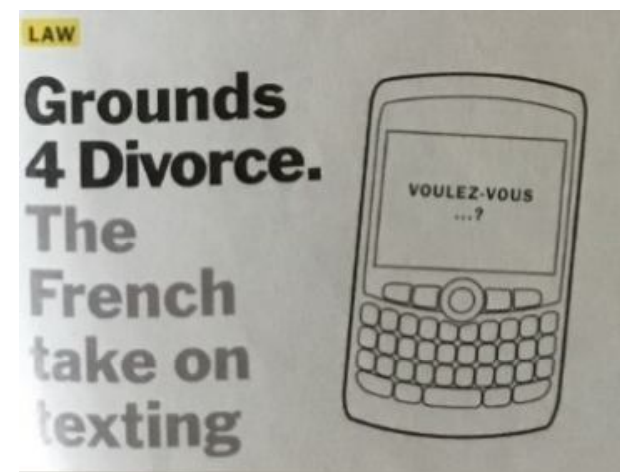

Рис. 20 [36, с. 37]

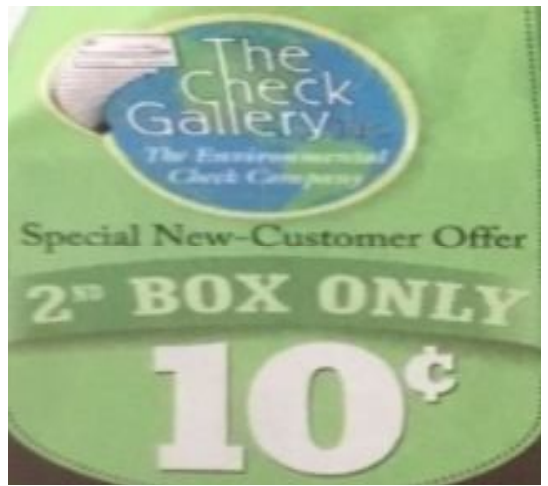

Рис. $21[13$, с. 32]

Висновки. Отже, дужки у сучасному масмедійному комунікативному просторі крім типових ролей, репрезентують й низку атипових, будучи різними за розмірами, формою та кількісним складом. Корпус ілюстративного матеріалу дає підстави стверджувати, що вони виконують такі функції: уточнювальну, лаконічну, дейктичну, змістово-розгалужувальну, атрактивну, змістовидільну, акцентування уваги, змістотворчу, структурувальну, компресивну, а також указують на ініціальну та фінальну частини тексту. Реалізація перерахованих функцій можлива, якщо вони перебувають у вербальній дистрибуції. У процесі аналізу також вставновлено, що дужки без тексту не мають смислового навантаження.

Обраний фактичний матеріал дає підстави стверджувати, що цифри також виконують важливу роль в англомовному масмедійному комунікативному просторі. Без цифрового модусу комунікація мала б трансформований вигляд, оскільки усіх їх можна замінити вербальними відповідниками. Це принаймні збільшило б загальний обсяг інформації. Однак такі тактики не типові, хоча іноді саме їм надають перевагу.

Найчастіше цифри відображають вік, час, кількість, дату, грошові еквіваленти, вартість. Поруч з цим їх також активно залучають у випадку коли необхідним видається поруч з цифрами представити інформацію 3 використанням цифр та інших знаків пунктуації, разом 3 буквосполуками, що є частиною дат тощо. Крім того, такі цифри як два, чотири та вісім виступають повноцінними замінниками вербальних лексем i успішно справляються 3 покладеною на них роллю та функційним навантаженням. 
Як бачимо, цифри та дужки є невід’ємними комунікативно значущими та семантично навантаженими елементами сучасного англомовного масмедійного комунікативного простору. На підставі проведеного дослідження очевидним $є$ те, що вони поліфункційні та полісемантичні і покликані віддзеркалити як традиційні, так і нетрадиційні аспекти комунікації.

\section{References}

1. Biletska, Oksana. 2014. "Hrafichna forma postmodernistskoho khudozhnoho tekstu kriz pryzmu hrafichnoi linhvistyky". Nova filolohiya 60: 17-22.

2. Hrad, Natalia. 2014. "Suchasni multymodalni studii: modalna linhvistyka ta multymodalna stylistyka". Odeskyi linhvistychnyi visnyk 4:49-51. URL: http://nbuv.gov.ua/UJRN/olinv_2014_4_15.

3. Yefymenko, Viktoriia. 2013. "Intertekstualni zviazky mizh tekstovymy svitamy kazkovykh tvoriv". Studia linguistica 7: 322-326.

4. Karp, Marta. 2016. "Vzaiemodiia zasobiv kontaminovanoi leksychnoi kohezii v teksti anhliyskykh multymodalnykh literaturnykh kazok Filipa Arda". Naukovi zapysky Natsionalnoho universytetu "Ostrozka akademiia". Seriia: Filolohiia 62: 136-139.

5. Marina, Olena. 2015. Semiotyka paradoksalnosti u kohnityvno-komunikatyvnomu vysvitlenni (na materiali suchasnoho anhlomovnoho poetychnoho dyskursu): monohrafiia. Kherson: Ailant.

6. Bezemer, Jeff. 2014. "Multimodal Transcription: a Case Study". Interactions, Images and Texts: a Reader in Multimodality. Berlin: De Gruyter Mouton 155-170.

7. Jewitt, Carey. 2008. "Multimodal Classroom Research". AERA Review of Research in Education 32: 241-267.

8. Kress, Gunther. 2003. Literacy in the New Media Age. London; New York: Routledge.

9. Norris, Sigrid. 2009. "Modal Density and Modal Configurations: Multimodal Actions". The Routledge Handbook of Multimodal Analysis / ed. by C. Jewitt. London; New York: Routledge 78-91.

10. O'Halloran, Kay. 2014. Multimodal Studies: Exploring Issues and Domains (Routledge Studies in Multimodality). 1st ed., $1-41$.

11. Van Leeuwen, Theo. 2004. Introducing Social Semiotics. London: Routledge.

\section{Sources of Exemplifying Material}

12. About Britannia. Digital Vidya. URL: https://www.digitalvidya. com/blog/relaunch-of-britannia-gooddaymade-a-significant-boost-in-its-perception-and-sales/ (дата звернення: 06.11.2017).

13. Advertising Leaflet. 2017. URL: http://www. hongkiat.com/blog/creative (дата звернення: 19.08.2018).

14. Contribute New York. 2006. No. 2. Vol. 1. May/June. 96 p.

15. Echo. 2018. No. 43, 758. Saturday, May, 26. 55 p.

16. Financial Times. 2010. No. 37, 271. Tuesday, March, 30.44 p.

17. Financial Times. 2010. No.26, 547. Thursday, March, 25. 58 p.

18. FT Weekend Magazine. 2009. No. 302. March, 28-29. 48 p.

19. FT Weekend. 2010. No. 37436. Saturday/Sunday, October, 9-10. 64 p.

20. International Herald Tribune. 2008. No. 39, 057. Saturday/Sunday, October, 4-5. 24 p.

21. International Herald Tribune. 2009. No. 39, 155. Thursday, January, 29. 22 p.

22. International Herald Tribune. 2009. No. 39, 175. Saturday/Sunday, February, 21-22. 20 p.

23. National Geographic. 2009. No. 1. Vol. 215. January. 154 p.

24. National Geographic. 2009. No. 4. Vol. 215. April. 154 p.

25. National Geographic. 2009. No. 6. Vol. 215. June. 141 p.

26. Newsweek. 2001-2002. No. 1. December / January, 31-7. 96 p.

27. Newsweek. 2004. No. 10. September, 6-13. 102 p.

28. The Daily Telegraph. 2009. No. 47, 943. Friday, July, 24. 62 p.

29. The Daily Telegraph. 2009. No. 48, 054. Tuesday, December, $1.62 \mathrm{p}$.

30. The Economist. 2014-2015. № 8918, Vol. 413. December/January, 20-2. $79 \mathrm{p}$.

31. The Independent. 2010. No. 7, 370. Tuesday, May, 27. 76 p.

32. The New York Times. 2010. No. 55, 051. Tuesday, May, 25. 68 p.

33. The Sun. 2018. Saturday, April, $28.72 \mathrm{p}$.

34. The Sun. 2018. Thursday, May, $10.60 \mathrm{p}$.

35. The Times. 2008. No. 69 289. Friday, April, 4.96 p.

36. Time. 2009. No. 10. Vol. 174. September, 14. 54 p.

37. Time. 2009. No. 6. Vol. 173. February, 9. 60 p.

Макарук Лариса. Структура, семантика и функции скобок и цифр в современном англоязычном масс-медийном коммуникативном пространстве. В работе проанализированы скобки и цифры как невербальные элементы, являющиеся составляющими одной из групп, которые в целом охватывают невербальные и паравербального компоненты, функционирующие в современном англоязычном массмедийном коммуникативном пространстве. К рассматриваемой нами группе «Непиктографические и нефотографические элементы» входят знаки препинания; диакритические знаки; типографские и другие вспомогательные знаки; цифры (числа) математические 
символы; аббревиатуры. В этом исследовании подробно освещена специфика скобок и цифр как интегральных модусов массмедийной среды.

Определены их семантические и структурные особенности, идентифицирована функциональная нагрузка, обоснованно их роль и назначение в современном англоязычном массмедийном коммуникативном пространстве. Кроме традиционного использования круглых скобок как знаков препинания в составе текста, которые дополнительно объясняют содержание, уточняют сказанное вне текста в скобках, активно привлекают квадратные, фигурные, атипичные видоизмененные (контекстуально зависимые).

Кроме типичных функций, скобки выполняют и ряд атипичных будучи разными по размерам, форме и количественному составу, в частности: уточняющую, лаконичную, дейктичную, содержательно-разветвительную, аттрактивную, содержательно-выделительную, акцентирующую внимание, структурующую, компрессионную, а также указывают на инициальную и финальную часть текста.

Установлено, что в англоязычном массмедийном коммуникативном пространстве цифры используют вместо лексем, графем и морфем. Они компрессируют количество традиционных графических элементов, входящих в состав одной лексемы. Бывают случаи, когда вместо словесного модуса используют цифровой, который выполняет роль лексемы. Цифровые модуса также бывают различных форм и размеров и имеют разные цветовые окраски. Выявлено, что наиболее распространенным является привлечение цифр четыре и два, которые замещают различные лексемы (for, four, two, to т.д.).

Ключевые слова: масс-медиа, коммуникативное пространство, скобки, цифры, функция.

Makaryk Larysa. The Structure, Semantics and Functions of Brackets and Numerals in the Contemporary English-Language Mass-Media Communicative Space. In this paper, as its title indicates, an analysis is presented of brackets and numerals, two specific non-verbal items in the general category of non-verbal and paraverbal elements which exist in the modern English-language mass media communicative space. By way of background, it could be mentioned that these items have been singled out from the overall category which may be termed "Non-pictographic and non-photographic elements" also includes other punctuation marks, as well as diacritical marks, typographic and other auxiliary signs, mathematical symbols, and abbreviations. As noted above, this study focuses in detail on the specific features of numerals and various types of brackets as integral modes within the media environment.

Their semantic and structural features are outlined, their functions are identified, and their role and purpose in the modern English-language mass-media communicative space are substantiated. The customary textual function of parentheses and square brackets as punctuation marks has been to enclose explanatory information regarding the content of the text, or to clarify what is expressed outside the parenthesized text. However, in addition to these features and functions, reference can be made to braces and 'curly' and atypical modified (contextually dependent) brackets, which can perform non-traditional functions through differences in size, shape and quantitative composition, being deictic, content-branching, focusing, structuring, and compressive and clarificatory.

Our study also demonstrated that in the English-language mass media communicative space, numerals may carry out the function of lexemes, graphemes and morphemes. They can be compressive in that they make it possible to reduce the number of traditional graphic elements that are part of a single lexeme. There are cases where a numeric character can act as a lexeme when used in place of the verbal expression. (This occurs most frequently with the numbers 2 and 4, which can take the place of the verbal units 'two', 'to', and 'too', and of 'four', 'fore', and 'for', as well as of syllables within longer words which contain these phonemes. These functions of these numerals can also be expanded by the use of differing shapes, sizes and colors.

Key words: mass-media, communicative space, brackets, numbers, function.

DOI: https://doi.org/10.32782/2410-0927-2020-12-22

УДК 811.111 '42

Наталія Одарчук, Тетяна Мірончук

\section{TED-конференції - платформа для англомовного мотиваційного дискурсу}

Останнім часом TED-конференції стали однією 3 найпопулярніших платформ у світовій спільноті для поширення ідей, гідних наслідування. Виголошені англійською мовою промови, присвячені мотивації, посідають чільне місце серед численних виступів науковців, медиків, програмістів, музикантів, просто пересічних громадян, які готові поділитися ідеєю, вартою поширення. У статті піддані аналізу виступи ораторів TED-конференцій 3 метою доведення їхньої мотиваційної спрямованості. Для реалізації мети спершу з'ясована семантика поняття мотивації, а далі на основі відібраних промов декількох спікерів із платформи TED проаналізоване семантичне наповнення їхньго тексту. Задля встановлення найуживаніших лексичних одиниць створене семантичне ядро кожного виступу. Виокремлення й аналіз семантичного ядра промов дозволяє переконатися в тому, що найуживаніші лексичні одиниці

(C) Одарчук Н., Мірончук T., 2020 